\title{
Mulches reduce aphid-borne viruses and whiteflies in cantaloupe
}

\author{
Charles G. Summers \\ Jeffrey P. Mitchell \\ James J. Stapleton \\ $\nabla$
}

We compared reflective plastic and wheat straw mulches with conventional bare soil for managing aphidborne virus diseases and silverleaf whitefly in cantaloupe. The occurrence of aphid-borne virus diseases was significantly reduced with both mulches as opposed to bare soil, and reflective plastic performed better than wheat straw. Silverleaf whitefly numbers, both adults and nymphs, were reduced equally by plastic mulch and wheat straw, and were significantly lower than with bare soil. Reflective plastic produced mature melons sooner and more cartons per acre than the other production systems. The reflective plastic system also produced a greater number of large-size melons, which are favored in the late-season market. Plants grown over straw mulch produced higher overall yields, including largesize melons, than those grown over bare soil.

A phid-borne viruses and silverleaf whitefly can completely devastate cantaloupe crops, causing serious economic losses to growers. The California Melon Research Advisory Board (2003) lists the management and control of aphid-borne viruses and whitefly as a top pest-management research priority. At the UC Kearney Research and Extension Center (KREC), we studied the use of reflective plastic mulch and straw mulch to manage aphid-borne viruses and silverleaf whitefly in cantaloupes without the use of pesticides.

Late-season cantaloupes are grown on approximately 5,000 acres on the
West Side of the San Joaquin Valley (John LeBoeuf, Pest Control Advisor, California Melon Research Advisory Board, personal communication). While susceptible to a number of diseases and insect pests, by far the most important problem over the past several years has been the complex of aphid-borne viruses, primarily cucumber mosaic virus (CMV), watermelon mosaic virus (WMV) and zucchini yellow mosaic virus (ZYMV), which vary in severity by season (Hartz et al. 1996). Disease severity increases as the growing season progresses, and fall is the worst time of the year for all of the viruses. The viruses kill and stunt plants, reducing yield.

These diseases are transmitted by several aphid species (Kennedy et al. 1962) that are commonly found in the San Joaquin Valley, and they are characterized by leaf symptoms including severe distortion (crinkled, puckered and misshapen), yellowing, and lightand dark-green mottling (mosaic symptoms). These viruses may occur singly
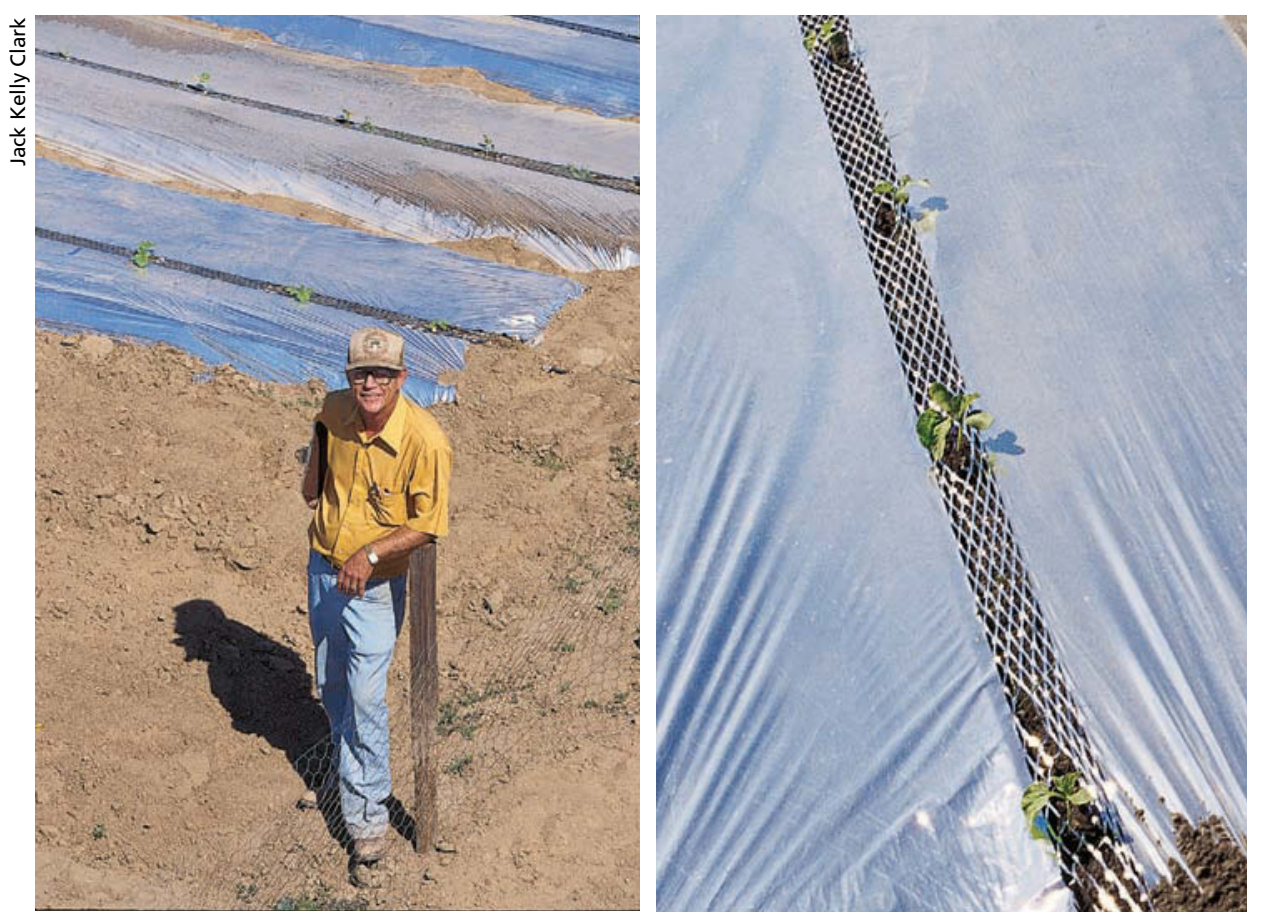

Kearney-based entomologist Charlie Summers, left, has been studying the use of mulches to limit damage to melons from silverleaf whitefly and virus-carrying aphids. Reflective plastic mulch with a lattice network cut down the center, right, can be applied following machineplanting. The plants emerge through the holes in the lattice network.

or in combination and can only be distinguished from each other serologically. We did not attempt to distinguish between the viruses in this study.

Recently, the silverleaf whitefly (Bemisia argentifolii Bellows and Perring) has emerged as a serious late-season pest, resulting in a $13 \%$ decrease in cantaloupe acreage in Fresno County (Jetter et al. 2001). Whiteflies damage cantaloupe by sucking the juices out of the plants, which can kill young plants and severely stunt older ones, resulting in almost no fruit set. While silverleaf whitefly transmits a number of viruses (Gemini viruses) in other parts of the United States, no whitefly-borne viruses have been found so far in California.

Currently, there are no cantaloupe varieties resistant to the aphid-borne viruses (CMRAB 2003). In addition, insecticides offer little relief because the viruses are acquired by the aphids and transmitted to the plants within seconds, long before the aphid vector acquires a lethal dose of insecticide

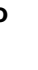



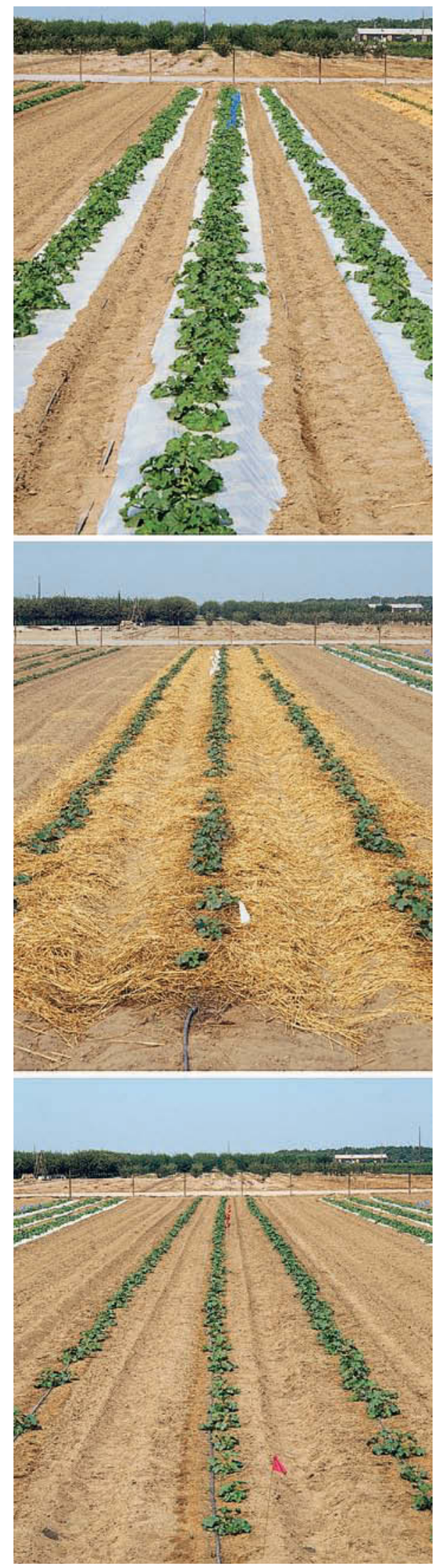

Reflective mulch, top, is made from a thin coat of aluminum adhering to a sheet of polyethylene. Unlike black or clear plastic mulches, UV light is reflected back into the sky and canopy, repelling insects and boosting plant growth. Wheat straw mulch, middle, also reduced virus diseases and whitefly infestations over plants grown on bare soil with no mulch, bottom.

\section{When grown over reflective plastic mulch, cantaloupes can produce both acceptable yields and sizes even under heavy pressure from aphid-borne viruses and silverleaf whitefly, without multiple insecticide applications.}

(Gibson and Rice 1989). Insecticides may actually enhance the spread of aphid-borne viruses by stimulating vector activity (Ferro et al. 1980). Many insecticides stimulate the aphid's nervous system, causing it to move from plant to plant very rapidly. This results in the infection of more plants than would occur in those visited by a nonintoxicated aphid, which settles down and feeds on one plant before moving to another one. This occurs before the insecticide has a lethal impact on the aphid. In contrast, whitefly infestations can be somewhat relieved by imidacloprid, a systemic insecticide. However, the development of resistance to imidacloprid and other insecticides among whiteflies is a major concern (Prabhaker et al. 1998; Elbert and Nauen 2000; CMRAB 2003).

\section{Mulches reduce crop viruses}

Reflective, metalized plastic mulch, formed by adhering a thin coat of aluminum ions to a sheet of polyethylene, has been shown to help control other types of aphid-borne viruses as well as whiteflies. This control is due to the fact that reflective plastic mulch reflects ultraviolet (UV) wavelengths, unlike black or clear plastic mulches. Flying aphids and whiteflies are repelled by these UV wavelengths. The outcome is to delay and reduce the incidence of aphid-borne viruses. Stapleton and Summers (2002) showed that the onset of virus disease symptoms was delayed by 3 to 6 weeks in plants grown over this mulch, which was critical for normal flowering and fruiting. In addition, reflective plastic mulch delayed and reduced the severity of silverleaf whitefly infestations in zucchini squash, pumpkins and cucumber (Summers and Stapleton 2002). This mulch was as effective as a preplant application of imidacloprid in managing whiteflies.

Reflective plastic mulch can be applied with ordinary mulch-laying equipment or by hand, and holes are then cut into the mulch to accommodate hand-planting. In addition, a version of this mulch has a lattice network of openings down the center and can be applied following machine planting; the plants then emerge through the openings. (Reflective plastic mulch is slightly more expensive than black plastic mulch, but the latter does not work to repel aphids or whiteflies.)

As part of a conservation tillage study, we also found that wheat straw mulch can help manage aphid-borne viruses and whitefly in cucurbits. In zucchini squash grown over straw mulch, yields were as high and the incidence of aphidborne virus diseases was no greater than in plants grown over reflective plastic mulch (Summers et al. 2004b). Plants grown over straw mulch produced higher yields than those grown over plots that had received a preplant application of imidacloprid. Straw mulch also deterred colonization by silverleaf whitefly and reduced the incidence of squash silverleaf (Summers et al. 2004b).

\section{Field study, sampling protocols}

In studies at KREC, we compared the effectiveness of reflective plastic and wheat straw mulches for the management of aphid-borne viruses and silverleaf whitefly in cantaloupe. We also compared both strategies to conventional bare soil production.

The study field was prepared for planting using conventional procedures: disking, preirrigation, fertilizer application (500 pounds per acre of 15-15-15 [nitrogen-phosphorus-potassium]), herbicide application (soil incorporated bensulide [Prefar] at 6.5 quarts per acre) and bed shaping (60-inch beds). The reflective plastic mulch was applied using standard mulch-laying equipment. Surface drip-tape was laid down the center of each bed under the plastic. Drip tape was also placed down the center of all remaining beds. The wheat straw was spread by hand. To accommodate seeding, holes were cut every 30 inches into the plastic mulch and the straw was "scratched" aside every 30 inches down the center of the beds.

Each treatment consisted of three beds with two unplanted beds between 




Left, a complex of different mosaic viruses can cripple crop production by stunting plant growth and reducing yield or killing cantaloupe plants outright. Middle, silverleaf whitefly has emerged as a serious late-season pest, contributing to a $13 \%$ decline in Fresno County cantaloupe acreage. Right, the cotton/melon aphid is a highly efficient vector of three mosaic viruses (cucumber, watermelon and zucchini yellow).

treatments. Plots were 220 feet long and replicated five times in a randomized complete block design. Three seeds were planted per hill, and following seedling emergence, the stand was thinned to one plant per hill for an average of 88 plants per bed. 'Top Mark' melons were planted on July 21, 2002, and 'Ovation' were planted on July 31, 2003.

Biomass. Biomass was sampled in 2003 as a measure of plant growth. Beginning 1 week after seedling emergence, one plant from a guard row of each plot (one of two rows on either side of the data-collection row) was selected at random, cut at the soil surface and placed in a paper bag. It was then returned to the laboratory, dried at $160^{\circ} \mathrm{F}$ and weighed.

Insects and disease. Following seedling emergence, 10 plants in the middle of each center row were marked with surveyor's flags. Beginning approximately 2 weeks after seedling emergence, the newest fully expanded leaf on each marked plant was carefully turned over and the winged aphids and adult silverleaf whiteflies were counted. At approximately 4 weeks after emergence, a 3-week-old leaf from each marked plant was removed, placed in a locking plastic bag and returned to the laboratory. A 1-square-inch plug was removed from each leaf and the number of silverleaf whitefly nymphs present was counted. The 10 marked plants were visually examined weekly for virus disease symptoms.

Yields. Melons from the center row of each plot were harvested at full slip (when the melon separates from the stem with a very slight pressure). Harvesting occurred over a 10- to 14day period. Melons were sorted by size, and the number in each size category was determined. Then weights in each size category were taken. The number of cartons per acre for each size category was then calculated.

Statistical analysis. All data presented in the text and figures were analyzed by analysis of variance. Means followed by the same letter(s) are not significantly different at $P=0.05$, using Fisher's protected LSD.

\section{Plant growth compared}

During the first 2 weeks of the 2003 study, plant growth was identical across all three production systems (reflective plastic mulch, wheat straw mulch and bare soil)(fig. 1). However, at 2 weeks the plants grown over the reflective plastic mulch began a rapid growth spurt; at 3 weeks, they had accumulated twice as much dry matter as plants grown on bare soil, and more than three times as much by 4 weeks.

The large increase in weight per plant observed on Sept. 21 reflects the earlier development of fruit in plants grown over plastic. Similarly, plants grown over straw mulch also accumulated dry matter more rapidly than those grown over bare soil. However, this dry matter increase was not as rapid as that in plants grown over reflective plastic. In earlier studies, we found that compared to straw mulch and bare soil, reflective plastic reflects a significantly higher rate of photosynthetically active radiation (PAR) back into the plant canopy (Summers et al. 2004a). This reflected PAR is intercepted and absorbed by the canopy, resulting in increased photosynthesis, which in turn results in increased plant growth. While not as efficient as reflective plastic, straw mulch still reflects twice as much PAR back into the canopy as bare soil (Summers et al. 2004a). We believe that this reflected PAR from the plastic and the straw mulch confers a growth advantage to plants.

\section{Aphid numbers and virus incidence}

In 2002 and 2003, the cotton/melon aphid (Aphis gossypii) was the only aphid species present. This aphid is a highly efficient vector of all three viruses. In 2002, there appear to have been two aphid flights (a large number of winged aphids flying for a period of time) after seedling emergence, in mid-August and mid-September. During mid-August 2002, the number of winged aphids per leaf was significantly higher on plants grown over bare soil than on those grown over plastic or straw mulch (fig. 2A). The higher aphid counts in plants grown over bare soil resulted in a significantly higher incidence of virus disease in late August and early September (fig. 2B). At the same time, significantly lower aphid counts in plants grown over straw and plastic mulch resulted in lower virus incidence. The reflective plastic mulch maintained virus incidence below 10\% through mid-September.

In 2003, a major aphid flight occurred in early August and populations of

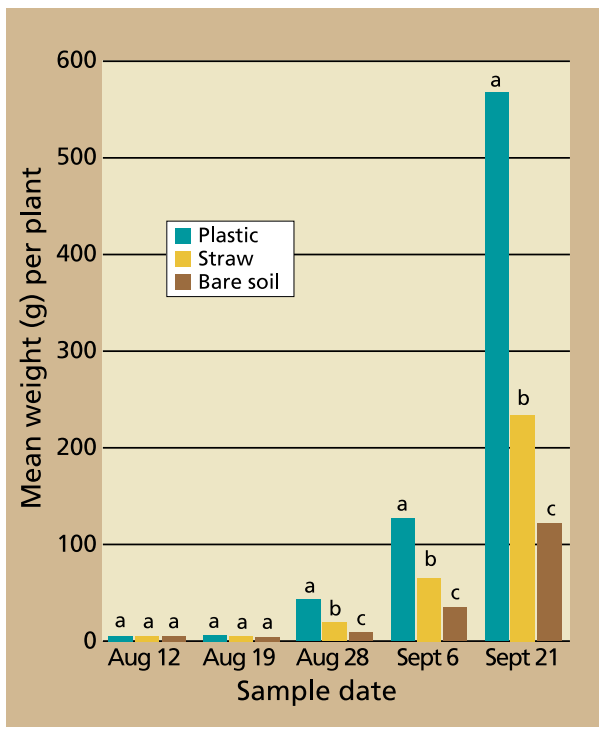

Fig. 1. Biomass accumulation in cantaloupe plants grown under three production systems, 2003. 


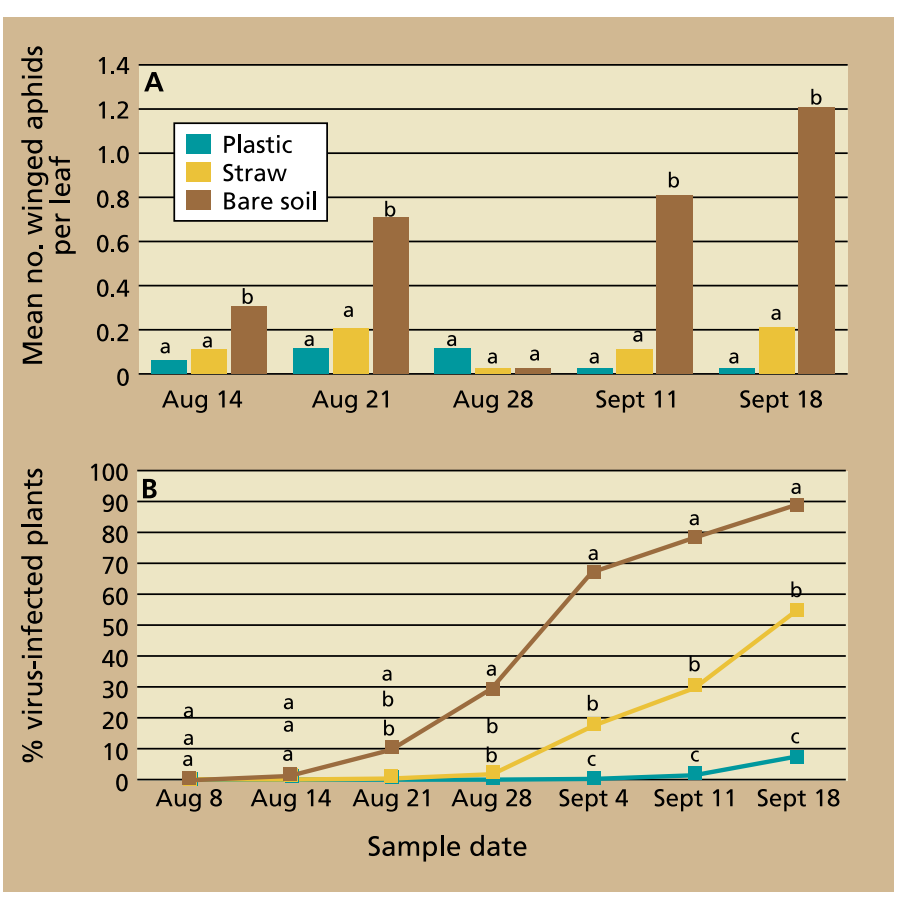

Fig. 2. Populations of (A) winged aphids and (B) virus disease incidence and in cantaloupe plants grown under three production systems, 2002.

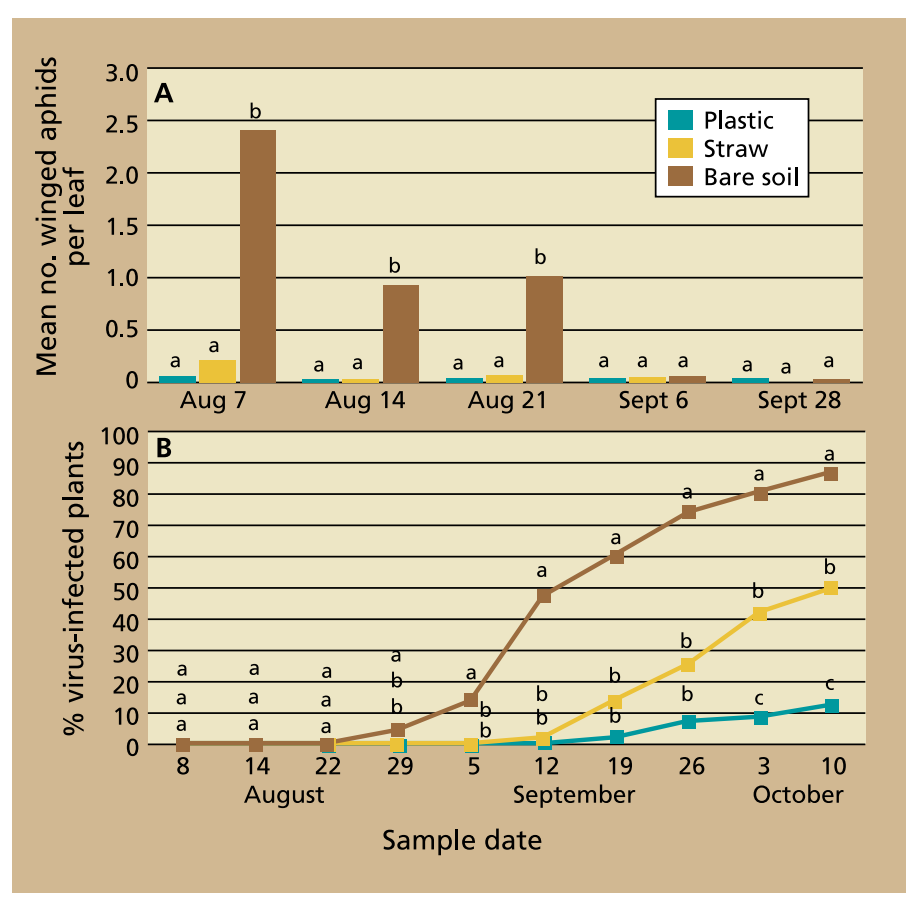

Fig. 3. Populations of (A) winged aphids and (B) virus disease incidence in cantaloupe plants grown under three production systems, 2003. winged aphids were very high a week after seedling emergence. Maximum aphid numbers again occurred in plants grown over bare soil (fig. 3A). The incidence of virus-infected plants closely followed that of winged aphids per leaf, with the highest percentage of infected plants grown over bare soil (fig. 3B). Disease incidence in plants grown over bare soil increased rapidly beginning in early September and peaked near 100\% by early October. The infection rate in plants grown over straw mulch remained under $50 \%$, while those grown over reflective plastic reached only $15 \%$.

\section{Whitefly populations}

In both 2002 and 2003, adult whitefly numbers were significantly higher in plants grown over bare soil (fig. 4). Whitefly numbers per leaf in 2002 were approximately twice those observed in 2003 with both mulches and bare ground. Whitefly numbers were significantly $(P<0.05)$ fewer, however, in plants grown over both reflective plastic and straw mulch in both years. While whitefly densities increased as the season progressed, numbers in plants grown over reflective plastic and straw mulch remained low (fig. 4A). Even in mid-September, the number of adults per leaf in plants grown over these mulches was less than those in bare soil in mid-August (fig. 4A).
The number of whitefly nymphs per square inch of leaf surface closely paralleled the adult counts, with populations in plants grown over reflective plastic and straw mulch significantly $(P<0.05)$ below those in bare soil. This trend persisted throughout the season (fig. 4B). The overall density of nymphs in 2003 was double that in 2002 for both mulches

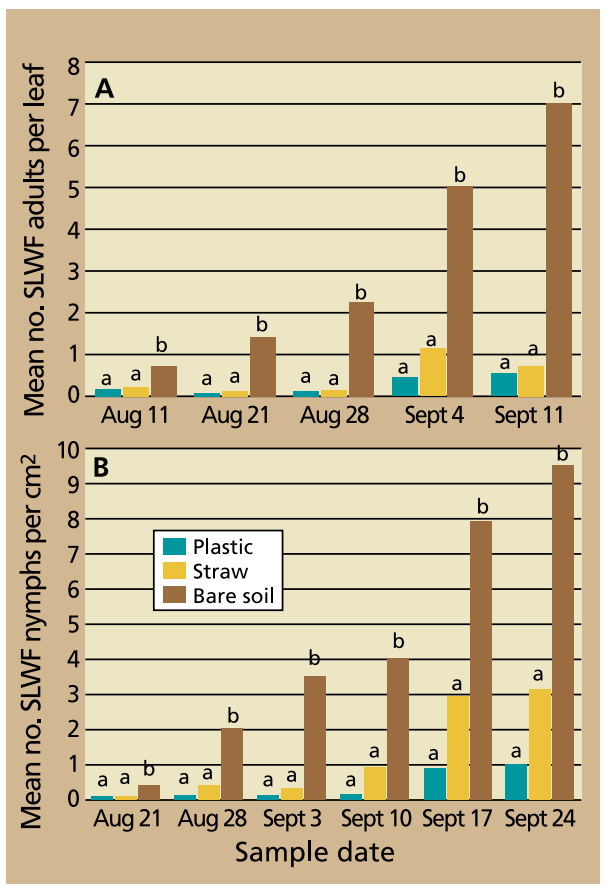

Fig. 4. Populations of silverleaf whitefly (SLWF) (A) adults and (B) nymphs in cantaloupe plants grown under three production systems, 2002. and the bare ground plots, although adult densities were just the reverse. Adult densities were higher in 2003 because the temperatures in August and September were considerably warmer, with daily maximums $3^{\circ} \mathrm{F}$ to $5^{\circ} \mathrm{F}$ higher than in 2002 (National Weather Service 2004). This resulted in an additional one-half generation of whitefly (eggs were laid and immature insects developed but did not reach the adult stage) in 2003. Unlike squash and pumpkin, cantaloupe does not show symptoms of squash silverleaf.

\section{Earlier, greater yields with mulch}

Melon plants grown over reflective plastic mulch produced ripe fruit 7 to 10 days earlier than those grown over either straw mulch or bare soil. In 2002, yields (cartons per acre) were significantly lower in all size categories in all three production systems. There were no large-size melons (\#12) in any production system in 2002. Among the remaining sizes, production was significantly $(P<0.05)$ higher in plants grown over plastic mulch, followed by those grown over straw mulch. Both production systems resulted in significantly higher yields than the conventional bare soil system (fig. 5).

While yields were significantly higher in all sizes in 2003, the same general trend was observed in 2002. Total 
